intermediate minima or to extend the ephemerides to Igr8 or later. The lists are practically confined to stars visible in European latitudes.

The Origin of Comets.-In an article which appears in the August issue of Scientia (vol. xxiv., p. 85), Prof. E. Strömgren gives an interesting account of the reasons for regarding comets as permanent members of the solar system. In recent years exact calculations have shown that comets which have appeared to traverse hyperbolic orbits, when in the neighbourhood of the sun, acquired the hyperbolic form in consequence of the perturbations to which they were subjected by the planets. It is accordingly concluded that comets belong to our system, and that the so-called non-periodic comets are merely comets which have very long periods. The possibility of a comet entering our system from without is not excluded, but it is stated that no case of this kind is yet known. By reference to the dynamics of starclusters it is argued that, while remnants of nebulous matter would, in general, be retained within the systems formed by individual suns, those which originally occupied the intermediate spaces would escape from the galactic system on account of the high velocities corresponding with their small masses. On this view, comet-forming materials would not exist in interstellar space.

Solar Physics Observatory Report.-The fifth annual report of the director of the'Solar Physics Observatory, Cambridge, relating to the year ending March $3^{I}$ last has been received. A study has been made of the South Kensington series of photographs of the spectrum of $\beta$ Lyræ, and information has been gained as to the best epochs for further records with comparison spectra. Further investigations of the hydrocarbon-band lines in stellar spectra have indicated a sequence in which there is a gradual strengthening of the hydrocarbon lines from type $F$ to type $G$, and a gradual weakening of the same lines from the $G$ to the $M$ type. Photographs of the sun's disc in calcium light were obtained on $16 \mathrm{I}$ days, and of prominences at the limb on $\mathrm{I}_{53}$ days; the disc spectroheliograms provide records for fourteen days which were missed in the Kodaikanal series. Numerous photographs of sunspot spectra were also obtained, and a comprehensive table of the affected lines recorded by various observers has been prepared. The necessity for a daily reference photograph of the sun's disc has led to the utilisation for this furpose of the image-lens of $60 \mathrm{ft}$. focal length which forms part of the McClean solar installation; by the use of slow bromide paper the photographs obtained have proved to be of greater value than was anticipated, inasmuch as they present the faculæ as well near the centre of the disc as near the limb. These photographs seem likely to be of special value in the elucidation of the relation between faculæ and flocculi. Investigations connected with the national defence have also been undertaken.

\section{BRITISH SCIENTIFIC INSTRUMENTS AND} PRODUCTS.

F the lectures delivered at the British Scientific Products Exhibition, organised by the British Science Guild at King's College, a feature common to all is the disclosure of the backward state of the industries with which they were respectively concerned when the war broke out. In radiology the outbreak of war four years ago found a condition of unpreparedness in common with other branches of medicine. It was necessary to provide large quantities of new apparatus and the adequate staff for many new departNO. 2548, VOL. IOI] ments. This state of affairs was described by Dr. R. Knox in the course of a lecture on the practical uses of radiography; and the backward state of the industry which he described as prevailing four years ago is all the more remarkable when we remember that although the X-rays were discovered by Prof. Röntgen, the discovery, as Mr. A. A. Campbell Swinton, who presided at the lecture, pointed out, could never have been made but for previous scientific research carried out in England. Had it not been for the work of Faraday, the necessary high-tension electric currents would not have been available, while the Crookes high-vacuum tube with which the rays were produced was the result of the laborious and long-continued investigations of that veteran scientific explorer, Sir William Crookes, who, although eighty-six years of age, is still young enough to be an exhibitor at the exhibition. Mr. Campbell Swinton also pointed out that the two greatest advances made in connection with $\mathrm{X}$-rays since their original discovery were due in large measure to professors at King's College, the original Crookes "focus" tube having been adapted to X-ray purposes by Sir Herbert Jackson, and the recently invented Coolidge tube, though brought out in the United States of America, was based on the experimental results obtained by Prof. O. W. Richardson, also of King's College, working on lines laid down by Sir J. J. Thomson, of Cambridge

Though the industry associated with radiography is small, its importance is great and promises to become greater in the future. Dr. Knox stated that experience gained in the administration of X-ray departments on a large scale, such as had been possible during the past four years, had taught us the necessity for a standardisation of apparatus. Had this been achieved before the outbreak of war, as he considers it well might have been, the task of rapidly equipping numerous departments would have been easy and the standard of work done much more satisfactory than it has been under the conditions possible in war time. The lecturer emphasised the need for research in connection with the production of essential apparatus and X-ray tubes if we were to hold our own in competition after the war. Most important research work has been carried out in this country lately in connection with the accessory apparatus, and Dr. Knox stated that the intensifying and fluorescent screens at present in use are an advance on those we formerly imported from Germany. The manufacturers of X-ray plates have more than held their own, and the production of a trustworthy photographic paper upon which X-ray negatives may be produced directly is one of the achievements of the war period. The most striking of the recent applications of $\mathrm{X}$-rays and radium described by Dr. Knox is that used by Mr. Percival P. Cole in connection with his operative work on injury to the face and jaws. Another new development in plastic surgery is also associated with $\mathrm{Mr}$. Cole's name, the well-known depilatory power of $\mathrm{X}$-rays having been used for the destruction of hair in portions of the scalp and face which are used in plastic surgery. Dr. Knox insisted more than once in the course of his lecture on the need for encouraging research and bringing about the cooperation of all interested in the work. He said that steps are in progress with the view of forming a British school of radiology and physicotherapy.

In describing advances in bacteriology during the war, Dr. C. H. Browning, director of the BlandSutton Institute of Pathology of the Middlesex Hospital, mentioned that the need to overcome the poison of sepsis in wounds had stimulated profitable investigations on the properties of flavine and other dyestuffs as antiseptics. He emphasised the relation 
between biology and chemistry and physics, and said that the chemical manufacturers could be of special help by assisting in the production of new drugs, under the guidance of the observations of biologists. In this line Germany had been especially active in the past. The microscope furnishes another example of the German development of English ideas. At present the industry for all practical purposes has almost ceased to exist, but Mr. J. E. Barnard claimed that it was undergoing a process of transformation which at the close of the war would make the British microscope pre-eminent. Between $I 880$ and 1890 this country stood foremost in the microscope industry, but after that time it lost its position to Germany because the latter gave us an instrument which was much needed at that time, being simpler in design and easier to construct. The Germans turned out a type known as the "Continental Model" which was useful for laboratory purposes. There was an insufficient supply of the English instrument, and this fact, coupled with the high price of the British article. enabled the Germans to obtain pre-eminence in this field. Unfortunately, it became the fashion to use the German instrument; and although the English instrument was equally good, home makers had little chance owing to the orders passing to the Continent. As in the case of the British dye industry, the English microscope industry was in British hands, but was lost for preventable reasons.

This is practically the same tale as Dr. M. O. Forster had to tell with regard to British dye-making in the course of his lecture on August 26. Dr. rorster traced the decay of the British industry after 1870 , up to which time the principal competitors were the French manufacturers, but after the Franco-German War the German factories rapidly took the lead, and the period 1870 to 1880 must be recognised as that in which British dye-making was definitely overtaken by the German industry. The causes of this change are easy to recognise. The liberal Government subsidy to the German universities, wisely paid out of the enormous indemnity wrung from the defeated French nation, resulted in producing a rapidly increasing army of well-trained and enthusiastic young German chemists, who were quickly absorbed by the chemical factories. These were strengthened also by several older chemists, who, discouraged by the outlook for chemistry in this country, left the colour factories in which they had been working and returned to their own country in search of more agreeable conditions. Moreover, Prof. Hofmann had already left this country in 1865 , and, occupying the professorship of chemistry in Berlin University, was largely instrumental in building up the German school of organic chemistry. Dr. Forster said that ten to fifteen years would be required before this country would be able to equal the position of Germany in regard to dyemaking, and then only if the same principle of patient inquiry into scientific principles, liberal expenditure on chemistry and chemists, thoughtful attention to the requirements of customers, strict self-control in the distribution of profits, and constant devotion of these to further developments were observed. The establishment of synthetic indigo manufacture on a commercial basis was the outcome of close and systematic study by a large number of German chemists, who were subsidised by a company sufficiently courageous to spend money in this manner rather than distribute it as dividends to shareholders. It is only by following these same processes of development that we can earn the right to take credit to our countrymen for the aniline colour industry.

NO. 2548 , VOL. IOI]

\section{HIGH-TENSION MAGNETOS.}

THE British Scientific Products Exhibition at King's College, London, organised by the British Science Guild, provides many encouraging examples of the success of British engineers in applying the results of scientific research. Many visitors interested in applications of electrical science are impressed by the range of magnetos exhibited, not only because it represents the successful establishment in Great Britain of an industry which was formerly a German monopoly, but also because the development of that industry has accelerated progress in numerous branches of scientific industry. It is no exaggeration to say that the degree of success achieved in the development of the combustion motor has at all stages been primarily dependent upon the efficiency of the ignition system used, and that the rapid strides which have during recent years been made in the construction of the petrol motor have mainly resulted from the very satisfactory high-tension ignition system that has been available.

During the past twenty years we have witnessed the birth and healthy development of high-tension ig: nition in the form of the magneto, and the wonderful efficiency of this system, coupled with its extreme flexibility-enabling one magneto to cope with almost any number of cylinders-is primarily responsible for the enormous advances which have taken place in the application of the petrol motor to industrial and, in more recent times, to war purposes Prior to the outbreak of war the number of high-tension magnetos being produced in this country formed a negligible proportion of the total number used for a variety of purposes. Through laxity on our part, this most vital "key" industry was allowed to develop in Germany, but it is satisfactory to know that the war has taught us a lesson in this respect, and the exhibition demonstrates how effectively this lesson has been learned. During the past four years three hundred thousand magnetos have been manufactured for war service alone, and what is even more important is that, according to those in a position to judge, the British magneto, as at present constructed, is more than equal to the pre-war Bosch magneto emanating from Stuttgart. This is sufficient testimony that British manufacturers have done their duty.

All electrical systems of ignition are direct descendants of Faraday's great discovery of electro-magnetic induction in 1831 , when for the first time in the world's history he succeeded in producing a spark by electro-magnetic means. The first system of electric ignition ever used was devised by Lenoir in 1860 . $\mathrm{He}$ utilised the high-tension spark of a Ruhmkorff coil for ignition purposes, employing a high-tension distributor for connecting the secondary winding, first to one plug and then to the other. It is worth noting that the modern battery system of ignition now used extensively in America is strikingly similar to the old Lenoir system, even to the detail of introducing an extremely small air gap between the rotating metal brush and the distributor segment-a method of distribution that is now being followed on magnetos. Marcus appears to have been the first man to construct a magneto for ignition purposes. His was a low-tension machine having the now familiar form of $\mathrm{H}$-armature, the current induced in the winding being broken at pre-determined times in the cylinder by a system of cams and levers. This system was further developed in $1 \$ 98$ by Simms and Bosch, using a fixed $H$ armature and rotating segments for producing the necessary flux changes in the armature core. This is of special interest because afterwards, by the 